\title{
PENENTUAN KLASIFIKASI DENGAN CRISP-DM DALAM MEMPREDIKSI KELULUSAN MAHASISWA PADA SUATU MATA KULIAH
}

\author{
Shedriko $^{1}$, Muhammad Firdaus ${ }^{2}$ \\ ${ }^{1,2}$ Program Studi Teknik Informatika, Universitas Indraprasta PGRI \\ Jl. Nangka No 58C, Tanjung Barat, Jagakarsa, Jakarta Selatan - 12530 \\ 11 shedriko@gmail.com, ${ }^{2}$ dasurichi@gmail.com
}

\begin{abstract}
ABSTRAK
Universitas XYZ merupakan suatu perguruan tinggi yang memiliki mahasiswa yang relatif banyak. Keberadaan suatu tool prediksi kelulusan dalam suatu mata kuliah sangat diperlukan dalam menunjang proses belajar mengajar di universitas tersebut, untuk mendorong tingkat kelulusan yang diinginkan. Kelulusan mahasiswa dalam suatu mata kuliah dapat diprediksikan berdasarkan data masukkan yang menjadi parameternya. Banyak metode klasifikasi yang dapat digunakan dengan keunggulan dan kekurangannya masing-masing yang dapat digunakan untuk melakukan prediksi tersebut. Dengan menggunakan metodologi data mining CRISP-DM, yaitu mengkomparasi beberapa klasifikasi dalam supervised learning, dapat diperoleh nilai terbaik yang berkaitan dengan akurasi dan error. Klasifikasi yang diperbandingkan dengan menggunakan software Orange Data Mining tersebut adalah Naive Bayes (NB), Neural Network (NN), Logistic Regression (LR) dan Support Vector Machine (SVM). Objek penelitian dilakukan terhadap mahasiswa yang mengikuti mata kuliah PTI (Pengantar Teknologi Informasi). Tujuan dari penelitian ini adalah mendapatkan metode klasifikasi yang efektif dan efisien dalam menentukan kelulusan mahasiswa dalam suatu mata kuliah. Hasil penelitian menunjukkan bahwa SVM merupakan salah satu klasifikasi yang sangat robust.
\end{abstract}

Kata Kunci: crisp-dm, data mining, klasifikasi, kelulusan, prediksi.

\begin{abstract}
The university of XYZ is one univerisity with a bulk number of student. A prediction tool is needed to support the teaching process for the pass rate achievement. The pass of college student from one subject can be predicted on the base of input parameters. Many used classification methods have their own positive and negative impacts in prediction. By using CRISP-DM data mining methodology, which is comparing several supervised learning classification, it will be obtaining the best result regarding accuracy and error value. This classification which is supported by Orange Data Mining software, are Naive Bayes (NB), Neural Network $(N N)$, Logistic Regression (LR) and Support Vector Machine (SVM). The objects of the research are students in Introduction to Information Technology subject. The research purpose is determining the best classification method which is effective and efficient in the student pass of a subject.. The result denotes that SVM is one of robust methods in classification.
\end{abstract}

Key Word: crisp-dm, data mining, classification, the pass, prediction.

\section{PENDAHULUAN}

Penelitian ini dilakukan di Universitas XYZ yang merupakan salah satu universitas yang berlokasi di Jakarta, yang memiliki 5 fakultas yang salah satunya merupakan fakultas pasca sarjana. Universitas ini memiliki visi, di samping sebagai penyelenggara pendidikan yang berguna untuk mencerdaskan kehidupan bangsa sehingga kelak dapat meningkatkan taraf kehidupan para peserta didik, juga memiliki visi unik yaitu menjadi perguruan tinggi yang membantu mengentaskan kemiskinan yaitu dengan memberikan biaya pendidikan yang relatif murah dan terjangkau kepada para peserta didik. Biaya yang relatif terjangkau ini menarik minat banyak calon peserta didik untuk mendaftar menjadi mahasiswanya. Meskipun memberikan biaya pendidikan yang relatif murah, namun universitas tetap berfokus pada kualitas. Hal tersebut dibuktikan dengan peningkatan kualitas pengajar secara berkesinambungan serta kualitas peserta didik dan fasilitas belajar mengajar yang digunakan.

Dengan jumlah mahasiswa yang relatif banyak, kehadiran suatu tool mengenai perkiraan kelulusan mahasiswa dalam suatu mata kuliah sangat mendukung proses belajar mengajar. Sehingga dilakukan penelitian terhadap mahasiswa yang mengikuti mata kuliah 
Pengenalan Teknologi Informasi (PTI) dengan beberapa kelas yang diambil sebagai samplenya. Dalam data homogen tersebut diambil sejumlah 175 mahasiswa yang akan diamati parameter penilaiannya yang kemudian dianggap sebagai data training. Selanjutnya data tersebut akan diproses menggunakan application, yaitu model yang diperoleh dari data training yang digunakan untuk menentukan hasil dari suatu set data test baru (Han, Kamber, \& Pei, 2012). Menurut Han dkk terdapat 2 kategori penilaian tersebut, yaitu:

1. Descriptive, bertugas mencirikan atau mengklasifikasikan sifat-sifat data tertentu ke dalam suatu set data tujuan

2. Predictive, bertugas melakukan induksi atau rangsangan terhadap suatu set data untuk dapat melakukan proses prediksi atau ramalan atau perkiraan

Dari kategori penilaian tersebut, dapat kita pahami bahwa penelitian ini merupakan suatu prediksi dari parameter inputnya.

Dalam bukunya, Dean menyatakan bahwa dalam kumpulan banyak data terdapat informasi yang dapat merubah tidak hanya kondisi seorang pasien, tapi bahkan tatanan dunia (Dean, 2014). Ungkapan dari Dean tersebut merupakan gambaran dari data mining. Dengan melakukan ekstraksi data, maka akan diperoleh pola-pola tertentu. Dari pola-pola tersebut dapat dilanjutkan dengan menggunakan algoritma yang dipilih untuk menghasilkan prediksiprediksi, dimana penggunaan algoritma merupakan bagian dari machine learning (Manrai, 2020). CRISP-DM atau Cross-industry Standard Process for Data Mining merupakan metode yang menyediakan standar baku dalam data mning yang dapat diterapkan ke dalam strategi pemecahan masalah umum pada bisnis atau pada unit penelitian yang terdiri dari beberapa fase (Huber, 2018).

Sedangkan machine learning terdiri dari 3 jenis, yaitu Supervised Learning, Unsupervised Learning dan Reinforcement Learning (Hertzmann \& Fleet, 2012).

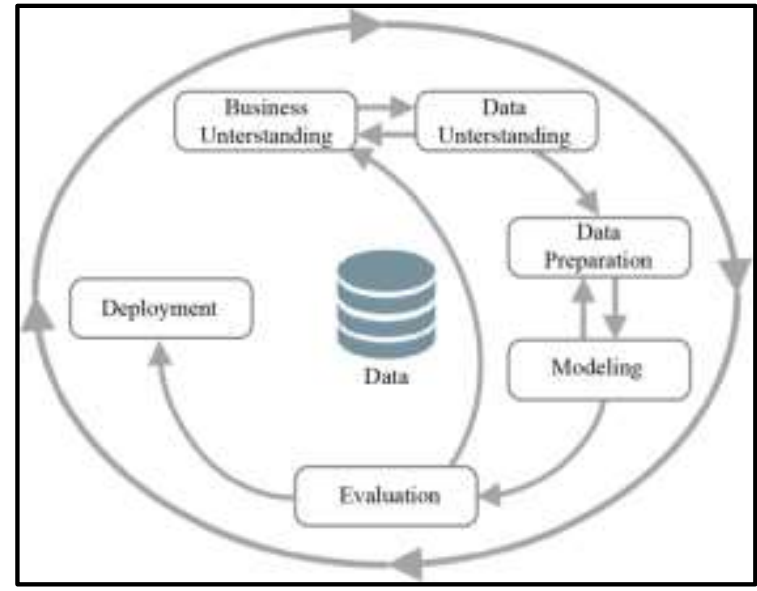

Gambar 1. Proses CRISP-DM (Huber, 2018)

Supervised Learning merupakan tipe pembelajaran dimana data training yang berisi jawaban yang benar diberikan terlebih dulu sebagai acuan. Banyak contoh algoritma yang masuk ke dalam kategori supervised, yang mana untuk penelitian ini akan diperbandingkan beberapa algoritma untuk mendapatkan yang terbaik berdasarkan nilai akurasi dan errornya, yaitu Niave Bayes (NB), Neural Network (NN) atau yang dikenal dengan Perceptron, Logistic Regression (LR) dan Support Vector Machine (SVM). Naive Bayes Classifier adalah kerangka kerja probabilitas untuk penyelesaian masalah klasifikasi, dimana naive dimaksudkan bahwa suatu fitur diasumsikan independent terhadap fitur lainnya yang tidak mungkin ada dalam dunia nyata, sedangkan bayes diambil dari nama seorang pembuat teorema statistik (Sawla, 2018). Perceptron atau Neural Network adalah model biologi neuron yang terdiri dari bobot dan bias yang adjustable (dapat diubah-ubah nilainya), yang dapat mengklasifikasi dengan hanya dua kelas, dimana algoritma ini akan melakukan konvergensi dan positioning posisi hasil pada bidang yang membagi dua kelas dengan memperbaiki nilai bobot terus menerus hingga posisi klasifikasi diperoleh (Bennamoun, 2003). Sedangkan Logistic Regression adalah metoda analisa statistika untuk mendeskripsikan hubungan antara dua atau lebih variabel terikat dengan variabel bebas (Kleinbaum \& Klein, 2010). Dan Support Vector Machine merupakan metode dalam Supervised Learning yang digunakan untuk mencari hyperplane terbaik dengan memaksimalkan jarak antar kelas (Deng, Tian, \& Zang, 2013). 
Tabel 1. Perbandingan Metode Klasifikasi

\begin{tabular}{|c|c|c|c|}
\hline 0 & Metode & Kelebihan & \\
\hline 1 & $\begin{array}{l}\text { Naive } \\
\text { Bayes (NB) }\end{array}$ & $\begin{array}{l}\text { 1. Bekerja baik pada } \\
\text { data training yang } \\
\text { sedikit } \\
\text { 2. Mengkonver-gensi } \\
\text { secara sangat cepat } \\
\text { dibanding model lain } \\
\text { 3. Dapat mengatasi fitur } \\
\text { yang tidak relevan serta } \\
\text { mendukung klasifikasi } \\
\text { biner dan multi-class }\end{array}$ & $\begin{array}{l}\text { 1. Fitur-fitur } \\
\text { independen, tidak ada } \\
\text { dalam dunia nyata } \\
\text { 2. Kesalahan akan terjadi } \\
\text { bila populasi tidak } \\
\text { terwakili } \\
\text { 3. Mengekstrak data } \\
\text { diskrit ke continue } \\
\text { berpotensi terjadi data } \\
\text { loss }\end{array}$ \\
\hline 2 & $\begin{array}{l}\text { Neural } \\
\text { Network } \\
(\mathrm{NN})\end{array}$ & $\begin{array}{l}\text { 1. Dapat bekerja baik } \\
\text { dengan data training } \\
\text { yang kurang } \\
\text { 2. Toleran terhadap } \\
\text { fault } \\
\text { 3. Robust terhadap } \\
\text { noise dari data training }\end{array}$ & $\begin{array}{l}\text { 1. Membutuhkan } \\
\text { processor yang bekerja } \\
\text { secara paralel } \\
\text { 2. Durasi penyelesaian } \\
\text { tidak dapat dipastikan } \\
\text { 3. Permasalahan tidak } \\
\text { terlihat dari iterasi }\end{array}$ \\
\hline 3 & $\begin{array}{l}\text { Logistic } \\
\text { Regression } \\
\text { (LR) }\end{array}$ & \begin{tabular}{|l|} 
1. Mudah, cepat dan \\
simple \\
2. Klasifikasi untuk multi \\
class capable \\
3. Variable independen \\
terhadap dependen \\
nampak jelas
\end{tabular} & $\begin{array}{l}\text { 1. Tidak capable pada } \\
\text { klasifikasi non-linier } \\
\text { 2. Dibutuhkan pemilihan } \\
\text { fitur yang tepat } \\
\text { 3. Kurang baik bila } \\
\text { terdapat data noise }\end{array}$ \\
\hline 4 & $\begin{array}{l}\text { Support } \\
\text { Vector } \\
\text { Machine } \\
\text { (SVM) }\end{array}$ & $\begin{array}{l}\text { 1. Dapat memberikan } \\
\text { solusi bagi masalah yang } \\
\text { kompleks } \\
\text { 2. Dapat menahan loss } \\
\text { sehingga memberikan } \\
\text { akurasi yang lebih baik } \\
\text { 3. Nilai optimal } \\
\text { minimum selalu dapat } \\
\text { dicapai }\end{array}$ & $\begin{array}{l}\text { 1. Menahan loss dapat } \\
\text { berakibat kurangnya } \\
\text { kerapatan informasi } \\
\text { 2. Perlakuan khusus } \\
\text { untuk parameter } \\
\text { hiperaktif } \\
\text { 3. Semakin besar datase } \\
\text { akan semakin besar pula } \\
\text { waktu trainingnya }\end{array}$ \\
\hline
\end{tabular}

(Shrestha, 2019; Varghese, 2018a, 2018b)

\section{METODE PENELITIAN}

Penelitian dilakukan dengan menggunakan data yang diperoleh melalui pengamatan parameter nilai input dan output terhadap mahasiswa yang mengikuti mata kuliah PTI (Pengantar Teknologi Informasi) yang berjumlah 175 orang, secara quantitatif (Kothari, 2004), untuk kemudian memprosesnya menggunakan metodology beberapa klasifikasi yang dipilih untuk diperbandingkan. Analisis dilakukan terhadap informasi yang sudah ada dengan melakukan perhitungan dari parameter input hingga menjadi output, dilanjutkan dengan menghitung nilai akurasi dan errornya, untuk membuat evaluasi kritis berkaitan dengan masalah tertentu (Kothari, 2004). Evaluasi tersebut dilakukan terhadap 4 jenis klasifikasi dengan melakukan langkah penghitungan yang sama dengan yang telah dijelaskan di atas, namun disesuaikan dengan rumusan masingmasing.

\section{HASIL DAN PEMBAHASAN}

Beberapa kriteria penilaian yang umum dilakukan pada kelulusan mahasiswa dalam suatu mata kuliah mencakup keseluruhan nilai dari kehadiran, tugas, ujian tengah semester, ujian akhir semester serta nilai-nilai penunjang lainnya seperti keaktifan di kelas dan kuis. Sehingga uraian dalam proses CRISP-DM nya adalah sebagai berikut (Hananto, 2017).

\section{Pemahaman Bisnis}

Tujuan bisnis dari penelitian ini adalah menentukan model klasifikasi yang tepat untuk dapat melakukan prediksi kelulusan yang baik dari beberapa model. Kondisi saat ini, belum adanya satu tools yang dapat digunakan untuk melakukan klasifikasi tersebut. Sedangkan tujuan dari data miningnya adalah model klasifikasi yang telah dipilih dapat memberikan nilai akurasi yang baik berdasarkan pola kelulusan yang ada berkaitan dengan parameter nilai inputnya.

\section{Pemahaman Data}

Pada fase ini dilakukan pengumpulan data awal sebagai syarat kelulusan dengan rincian sebagai berikut:

a. Nilai akhir harus mencapai nilai lebih besar atau sama dengan 56

b. Absensi harus memenuhi setidaknya 80 persen

c. Nilai tugas minimal 60

d. Menghadiri kuis yang diadakan

e. Aktif di kelas dengan bertanya atau menjawab pertanyaan-pertanyaan yang terlontar di kelas baik yang dikemukakan oleh dosen maupun mahasiswa pada sesi diskusi

Namun demikian, beberapa penilaian subyektif dapat saja terjadi dengan anggapan bahwa seorang mahasiswa mungkin lengah pada saat ujian, padahal dalam kegiatan belajar mengajar sehari-hari di kelas dosen melihat bahwa mahasiswa tersebut memiliki potensi yang cukup besar di perkuliahan tersebut. Data dideskripsikan sebagai berikut: nilai tugas diambil berdasarkan pengumpulan dari tugas yang diberikan termasuk kuis, nilai ujian tengah semester diambil dari ujian yang dilaksanakan pada tengah semester dan nilai akhir semester yang diambil pada akhir semester. 
3. Persiapan Data

Pada fase ini dilakukan pemilihan dan pembersihan data. Beberapa noise tetap dipertahankan untuk mewakili kondisi sesungguhnya di lapangan. Adapun atribut yang digunakan sebagai evidence dalam algoritma yang diperbandingkan pada penelitian ini terdiri dari 3 item, yaitu.

a. Nilai tugas

b. Nilai ujian tengah semester (UTS)

c. Nilai akhir semester (UAS)

Data yang menjadi nilai inputan tersebut nantinya akan dimasukkan ke dalam software pengolah data, yaitu Orange Data Mining. Software tersebut merupakan pengolah data mining open source yang cukup powerful disamping penggunaannya yang relatif mudah dan simple. Beberapa penampakan data training dimana mahasiswa dinyatakan tidak lulus dengan nilai target $=0$ dan lulus dengan nilai target $=1$ dapat dilihat pada tabel di bawah berikut ini.

Tabel 2. Beberapa data training yang menyatakan mahasiswa tidak lulus

\begin{tabular}{|c|r|r|r|r|r|}
\hline 1 & Nilai Tuga & Nilai UTS & Nilai UAS & Kelulusan & \multicolumn{1}{l|}{ Target } \\
\hline 2 & 9,0 & 5,0 & 2,8 & TIDAK LULUS & 0 \\
\hline 3 & 9,0 & 4,5 & 1,7 & TIDAK LULUS & 0 \\
\hline 4 & 0,0 & 3,0 & 0,0 & TIDAK LULUS & 0 \\
\hline 5 & 10,0 & 3,0 & 1,0 & TIDAK LULUS & 0 \\
\hline 6 & 0,0 & 0,0 & 0,0 & TIDAK LULUS & 0 \\
\hline 7 & 10,0 & 5,0 & 1,8 & TIDAK LULUS & 0 \\
\hline 8 & 8,0 & 5,0 & 1,8 & TIDAK LULUS & 0 \\
\hline 9 & 9,0 & 3,0 & 4,2 & TIDAK LULUS & 0 \\
\hline 10 & 0,0 & 0,0 & 0,0 & TIDAK LULUS & 0 \\
\hline 11 & 0,0 & 6,8 & 0,0 & TIDAK LULUS & 0 \\
\hline 12 & 9,0 & 6,2 & 2,8 & TIDAK LULUS & 0 \\
\hline 13 & 8,0 & 6,2 & 0,9 & TIDAK LULUS & 0 \\
\hline 14 & 9,0 & 5,0 & 2,1 & TIDAK LULUS & 0 \\
\hline 15 & 1,5 & 4,5 & 8,1 & TIDAK LULUS & 0 \\
\hline 16 & 1,5 & 6,8 & 6,8 & TIDAK LULUS & 0 \\
\hline 17 & 1,5 & 7,2 & 8,2 & TIDAK LULUS & 0 \\
\hline 18 & 1,5 & 9,0 & 3,5 & TIDAK LULUS & 0 \\
\hline 19 & 1,5 & 8,5 & 5,6 & TIDAK LULUS & 0 \\
\hline 20 & 0,0 & 0,0 & 0,0 & IIDAK LULUS & 0 \\
\hline 21 & 8,0 & 8,0 & 6,0 & TIDAK LULUS & 0 \\
\hline
\end{tabular}

Tabel 3. Beberapa data training yang menyatakan mahasiswa lulus

\begin{tabular}{|r|r|r|r|c|r|}
\hline 1 & Nilai Tugas & Nilai UTS & Nilai UAS & Kelulusan & \multicolumn{1}{l|}{ Target } \\
\hline 157 & 10,0 & 7,2 & 7,1 & LULUS & 1 \\
\hline 158 & 10,0 & 6,2 & 4,7 & LULUS & 1 \\
\hline 159 & 9,0 & 6,8 & 4,2 & LULUS & 1 \\
\hline 160 & 10,0 & 8,0 & 6,2 & LULUS & 1 \\
\hline 161 & 9,0 & 5,0 & 6,3 & LULUS & 1 \\
\hline 162 & 9,0 & 8,5 & 7,2 & LULUS & 1 \\
\hline 163 & 9,0 & 5,0 & 6,1 & LULUS & 1 \\
\hline 164 & 10,0 & 7,2 & 6,3 & LULUS & 1 \\
\hline 165 & 9,0 & 7,2 & 6,2 & LULUS & 1 \\
\hline 166 & 10,0 & 7,2 & 7,5 & LULUS & 1 \\
\hline 167 & 10,0 & 6,8 & 4,9 & LULUS & 1 \\
\hline 168 & 10,0 & 7,2 & 6,3 & LULUS & 1 \\
\hline 169 & 9,0 & 6,2 & 5,8 & LULUS & 1 \\
\hline 170 & 10,0 & 5,0 & 4,2 & LULUS & 1 \\
\hline 171 & 8,0 & 5,5 & 5,0 & LULUS & 1 \\
\hline 172 & 8,0 & 7,2 & 6,3 & LULUS & 1 \\
\hline 173 & 10,0 & 4,0 & 5,8 & LULUS & 1 \\
\hline 174 & 8,0 & 7,2 & 5,9 & LULUS & 1 \\
\hline 175 & 9,0 & 6,8 & 5,9 & LULUS & 1 \\
\hline 176 & 10,0 & 6,2 & 4,8 & LULUS & 1 \\
\hline
\end{tabular}

\section{Permodelan}

Pada pemilihan teknik permodelan diambil beberapa algoritma klasifikasi yang akan diperbandingkan untuk mendapatkan klasifikasi terbaik untuk memprediksi kelulusan mahasiswa dalam suatu mata kuliah. Algoritma yang diperbandingkan tersebut adalah Naive Bayes (NB), Neural Network (NN), Logistic Regression (LR) dan Support Vector Machine (SVM). Dalam membangun model, digunakan software Orange Data Mining, yang direkonstruksi sedemikian rupa sehingga suatu rangkaian model yang berkaitan dengan keempat algoritma tersebut di atas dibuat. Beberapa fitur yang disediakan oleh software ini adalah sebagai berikut:

$a$. Banyak menyediakan algoritma yang berbeda untuk machine learning dan data mining

b. Merupakan aplikasi open source dan tersedia secara bebas atau gratis

c. Platform yang dapat berdiri sendiri atau independent

d. Mudah digunakan oleh siapa saja, tidak hanya spesialis data mining

e. Fasilitas yang disediakan fleksibel untuk eksperimen

f. Dilakukan up-to-date secara berkala dengan penambahan fitur dan algoritma baru 


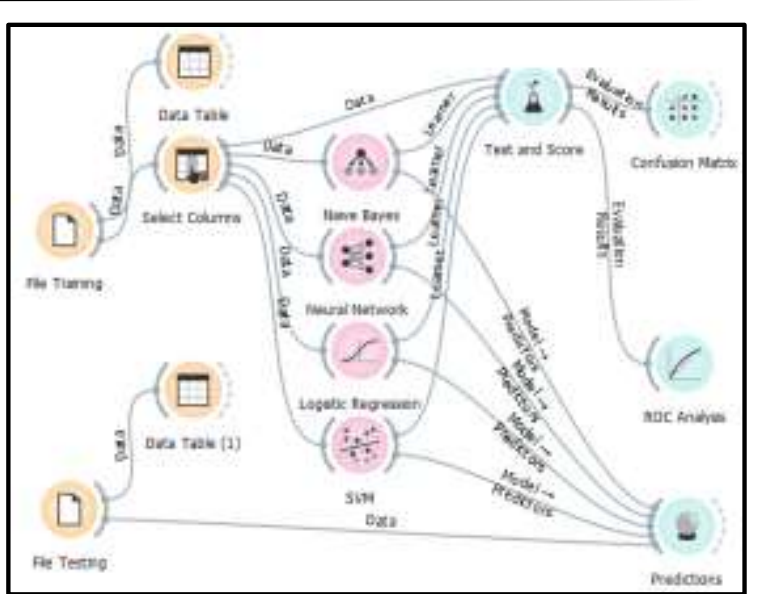

Gambar 2. Model CRISP-DM Penelitian Dengan Orange Data Mining

Penilaian model yang merupakan perbandingan akurasi model dari keempat model data mining dan algoritma machine learning yang diperbandingkan dapat dilihat pada tabel 4 . Akurasi merupakan nilai yang diperoleh dari hasil perhitungan jumlah nilai true positive dengan true negative yang dibagi dengan total populasi. Sedangkan error rate diperoleh dari hasil perhitungan dari jumlah nilai false positive dan false negative dibagi dengan total populasi. Dalam penelitian ini, total populasi yang diambil adalah 175 mahasiswa.

Tabel 4. Perbandingan akurasi dan error

\begin{tabular}{|l|c|c|}
\hline \multicolumn{1}{|c|}{$\begin{array}{c}\text { Classification } \\
\text { Algorithms }\end{array}$} & $\begin{array}{c}\text { Accuracy } \\
\text { Rate }\end{array}$ & $\begin{array}{c}\text { Error } \\
\text { Rate }\end{array}$ \\
\hline $\begin{array}{l}\text { Naive Bayes } \\
\text { (NB) }\end{array}$ & $89,7 \%$ & $10,3 \%$ \\
\hline $\begin{array}{l}\text { Neural Network } \\
\text { (NN) }\end{array}$ & $85,7 \%$ & $14,3 \%$ \\
\hline $\begin{array}{l}\text { Logistic Regression } \\
\text { (LR) }\end{array}$ & $88,6 \%$ & $11,4 \%$ \\
\hline $\begin{array}{l}\text { Support Vector } \\
\text { Machine (SVM) }\end{array}$ & $95,4 \%$ & $4,6 \%$ \\
\hline
\end{tabular}

Sedangkan nilai-nilai statistik lainnya dapat dilihat pada table 5. Dalam table tersebut diperlihatkan nilai yang merupakan Precision, Recall dan AUC (Area Under Curve), yang kesemuanya diklasifikasikan ke dalam 2 kelompok, yaitu lulus (passed) dan tidak lulus (failed), dengan menggunakan Orange Data Mining. Precision merupakan rasio prediksi benar positif dibandingkan dengan keseluruhan hasil yang diprediksi positif, sedangkan Recall merupakan rasio benar positif dibandingkan dengan keseluruhan data yang benar positif
(Arthana, 2019). Dan AUC merupakan daerah di bawah ROC yang digunakan untuk menentukan model yang terbaik dalam prediksi (Abhigyan, 2020).

Tabel 5. Perbandingan analisis statistik

\begin{tabular}{|l|l|r|r|r|}
\hline Algoritma & Class & Precision & Recall & AUC \\
\hline \multirow{2}{*}{ NB } & Passed & 0,935 & 0,935 & 0,947 \\
\cline { 2 - 5 } & Failed & 0,750 & 0,750 & 0,947 \\
\hline \multirow{2}{*}{ NN } & Passed & 0,848 & 1,000 & 0,902 \\
\cline { 2 - 5 } & Failed & 1,000 & 0,306 & 0,902 \\
\hline \multirow{2}{*}{ LR } & Passed & 0,89 & 0,993 & 0,971 \\
\cline { 2 - 5 } & Failed & 0,944 & 0,472 & 0,971 \\
\hline \multirow{2}{*}{ SVM } & Passed & 0,958 & 0,986 & 0,969 \\
\cline { 2 - 5 } & Failed & 0,938 & 0,833 & 0,969 \\
\hline
\end{tabular}

Kemudian, dengan menggunakan beberapa data testing, dilakukan pengujian terhadap keempat algoritma. Hasil pengujian dapat dilihat pada tabel 6.

Tabel 6. Hasil Pengujian

\begin{tabular}{|c|c|c|c|c|c|c|c|}
\hline 1 & $\begin{array}{c}\text { NB } \\
\text { Failed }\end{array}$ & $\begin{array}{c}\text { NN } \\
\text { Failed }\end{array}$ & $\begin{array}{c}\text { LR } \\
\text { Failed }\end{array}$ & $\begin{array}{l}\text { SVM } \\
\text { Failed }\end{array}$ & $\begin{array}{l}\text { Homework } \\
42\end{array}$ & $\begin{array}{l}\text { MidTest } \\
42\end{array}$ & $\begin{array}{l}\text { FinalTest } \\
42\end{array}$ \\
\hline 2 & Failed & Passed & Failed & Failed & 43 & 43 & 43 \\
\hline 3 & Failed & Passed & Failed & Failed & 45 & 45 & 45 \\
\hline 4 & Failed & Passed & Passed & Failed & 46 & 46 & 46 \\
\hline 5 & Failed & Passed & Passed & Failed & 58 & 58 & 58 \\
\hline 6 & Passed & Passed & Passed & Passed & 59 & 59 & 59 \\
\hline
\end{tabular}

Dari tabel hasil pengujian, terlihat bahwa nilai ambang kelulusan dari Naive Bayes (NB) terdapat pada nilai 58 dan 59, Neural Network (NN) pada nilai 42 dan 43, Logistic Regression (LR) pada nilai 45 dan 46, serta Support Vector Machine (SVM) pada nilai 58 dan 59.

\section{SIMPULAN DAN SARAN}

Dari beberapa parameter yang telah dijelaskan di atas, diperoleh hasil penilaian sebagai berikut:

1. Nilai precision kelas lulus tertinggi diraih oleh algoritma SVM

2. Nilai recall kelas lulus tertinggi diraih oleh algoritma LR

3. Nilai AUC tertinggi diraih oleh algoritma LR

4. Nilai akurasi tertinggi diraih oleh algoritma SVM

5. Nilai uji pada ambang kelulusan terhadap nilai yang diharapkan, poin tertingginya diraih oleh algoritma NB dan SVM

Kelima poin di atas menunjukkan, bahwa algoritma SVM memberikan 3 kali kemunculan dalam hal peraihan nilai tertinggi. Sementara 
algoritma LR muncul sebanyak 2 kali. Sedangkan NB hanya muncul sebanyak 1 kali. Sehingga dapat ditarik kesimpulan bahwa SVM merupakan algoritma yang terbaik yang dapat diambil sebagai tools dalam memprediksi kelulusan mahasiswa pada suatu mata kuliah. Dengan tetap mempertahankan noise yang terdapat pada data yang diolah, dapat disimpulkan bahwa SVM cukup robust dalam mengatasi anomali data pada penelitian ini. Penelitian ini dapat dijadikan acuan sebagai penilai dalam memprediksi kelulusan mahasiswa, tidak hanya pada mata kuliah Pengantar Tenologi Informasi, tapi juga untuk mata kuliah lainnya.

\section{DAFTAR PUSTAKA}

Abhigyan. (2020). Understanding The AUCROC Curve. Retrieved July 31, 2021, from medium.com website:

https://medium.com/analytics-

vidhya/understanding-the-auc-roc-curvecdc754d7b58a

Arthana, R. (2019). Mengenal Accuracy, Precision, Recall dan Specificity serta yang diprioritaskan dalam Machine Learning. Retrieved July 31, 2021, from medium.com website: https://rey1024.medium.com/mengenalaccuracy-precission-recall-danspecificity-serta-yang-diprioritaskanb79ff4d77de8

Bennamoun, M. (2003). Single Layer Perceptron (SLP) Classifiers. Lecture Slide of Neural Computation, University of Western Australia.

Dean, J. (2014). Big data, data mining, and machine learning [internet resource]: value creation for business leaders and practitioners. John Wiley \& Sons Inc.

Deng, N., Tian, Y., \& Zang, C. (2013). Support vector machines (SVM): Optimization Based Theory, Algorithms and Extension. CRC Press, Taylor \& Francis Group.

Han, J., Kamber, M., \& Pei, J. (2012). Data Mining: Concepts and Techniques (Third). https://doi.org/10.1016/C2009-0-61819-5

Hananto, V. R. (2017). Analisis Penentuan Metode Data Mining Untuk Prediksi Kelulusan Mahasiswa Sebagai Penunjang Angka Efisiensi Edukasi. Jurnal Ilmiah SCROLL, 5(1), 1-11.

Hertzmann, A., \& Fleet, D. (2012). Machine Learning and Data Mining. Computer Science Department, University of
Toronto.

Huber, S. (2018). A holistic extension to the CRISP-DM model. Science Direct, (12th CIRP Conference on Intelligent Computation in Manufacturing Engineering, 18-20 July 2018, Gulf of Naples, Italy).

Kleinbaum, D. G., \& Klein, M. (2010). Statistics for biology and health: Logistical regression (pp. 1-709). pp. 1-709.

Kothari, C. R. (2004). Research Methodology, Methods \& Techniques (Second Rev). https://doi.org/10.1016/0022460X(82) $90541-7$

Manrai, T. (2020). How Data Mining is Different Than Machine Learning. Retrieved July 26, 2021, from medium.com website: https://manraitarun.medium.com/how-data-mining-isdifferent-than-machine-learningcdcaf559d2a7

Sawla, S. (2018). Introduction to Naive Bayes for Classification. Retrieved July 28, 2021, from medium.com website: https://medium.com/@srishtisawla/introd uction-to-naive-bayes-for-classificationbaefefb43a2d

Shrestha, P. (2019). The Advantages and Disadvantages of Neural Networks. Retrieved July 28, 2021, from gkstuffs.com website: https://gkstuffs.com/futuretech/advantages-and-disadvantages-ofneural-networks/

Varghese, D. (2018a). Comparative Study on Classic Machine Learning Algorithms. Retrieved July 28, 2021, from towardsdatascience.com website: https://towardsdatascience.com/comparati ve-study-on-classic-machine-learningalgorithms-24f9ff6ab222

Varghese, D. (2018b). Comparative Study on Classic Machine Learning Algorithms Part-2. Retrieved July 28, 2021, from medium.com website: https://medium.com/@dannymvarghese/c omparative-study-on-classic-machinelearning-algorithms-part-2-5ab58b683ec0 